\title{
The value of audiovisual archives
}

\author{
Luís Felipe Toledo¹, Cheryl Tipp², Rafael Márquez³
}

\author{
${ }_{1}$ Fonoteca Neotropical Jacques Vielliard, Unicamp, Campinas, 13083-970, Brazil. \\ ${ }_{2}$ British Library, London, NW1 2DB, UK. \\ ${ }_{3}$ Fonozoo, Museo Nacional de Ciencias Naturales-CSIC, Madrid, 28006, Spain. \\ *Corresponding author. E-mail: toledolf2@yahoo.com
}

FOR CENTURIES, HUMANS have collected specimens and deposited them in scientific collections housed in zoological or natural history museums. Such documentation is essential for the recognition and classification of our extinct and extant biodiversity. As technology improved, we created DNA databases that have helped us to understand the evolutionary relationships between organisms. Both genetic archives and museum specimens are well recognized as important biodiversity repositories, and scientific literature routinely refers to them.

Equally important, but often overlooked, are audiovisual archives, which allow us to record complementary information that could not be recovered from dead specimens or DNA sequences. Sound archives are particularly interesting, as they capture behavior with great accuracy and are often involved in conspecific recognition. These digital archives are relatively inexpensive to store and curate, and are usually obtained with no harm to the focal species and no need for collection.

Unfortunately, audiovisual archives are being neglected; voucher numbers, which provide access to the files and the possibility of replication, are often not available in articles. Furthermore, the files are not always georeferenced, despite the importance of verifying the presence of certain taxa in a specific space and time. To raise the standards of documentation, we call for all scientific journals to require authors to deposit their audiovisual recordings in scientific collections or online repositories, just as they do for specimens, DNA sequences, and even raw data. 